\title{
Genomics and the chemotherapy of leprosy
}

\author{
JACQUES H. GROSSET* \& STEWART T. COLE** \\ *Laboratoire de Bactériologie et Hygiène, Faculté de Médecine Pitié- \\ Salpêtrière, 91 Boulevard de l'Hôpital, 75634 Paris, Cedex 13, \\ France \\ **Unité de Génétique Moléculaire Bactérienne, Institut Pasteur, 28 \\ Rue du Dr Roux, 75724 Paris, Cedex 15, France
}

\begin{abstract}
Summary The information deduced from the genome sequence of Mycobacterium leprae is of immense value for the chemotherapy of leprosy. Knowing the complete set of genes, enzymes and proteins allows us to understand why some drugs are without effect whereas others are fully active. It may also enable better use to be made of existing drugs, such as $\beta$-lactams, and opens new avenues for the development of novel compounds. $M$. le prae is relatively susceptible to a wide range of drugs, unlike the highly related tubercle bacillus, and several new multidrug regimens are in clinical trials. Genomics provides a number of possible explanations for this broader susceptibility as some of the genes encoding enzymes involved in antibiotic inactivation have decayed whereas the number of transporters available to contribute to drug efflux is considerably lower than in Mycobacterium tuberculosis. Several leads for new drug targets have been uncovered.
\end{abstract}

\section{Introduction}

The WHO-recommended multidrug therapy (MDT) for leprosy has been, without question, one of the major success stories in the field of public health. ${ }^{1}$ There is, however, no room for complacency as the incidence of detected cases of leprosy has not fallen during the last decade $^{2}$ and the spectre of drug resistance is never far away. This has been well illustrated by the increased spread of multidrug resistant tuberculosis during the last decade. ${ }^{3}$ Furthermore, regimens can always be improved by increasing ef ficacy or reducing duration and this is only likely to be achieved by employing drugs that are stronger or more effective than dapsone and clofazimine.

A number of compounds, such as minocycline, various fluoroquinolones and macrolides, have shown excellent activity in the mouse model of leprosy, and in limited clinical trials, ${ }^{4-6}$ and ROM, a new regimen for the treatment of single lesion paucibacillary leprosy, comprising rifampicin, ofloxacin and minocycline, ${ }^{7,8}$ has shown particular promise. In contrast to the situation in tuberculosis, where new chemotherapeutic agents are desperately

*Correspondence to: Prof. S.T. Cole, Unité de Génétique Moléculaire Bactérienne, Institut Pasteur, 28 Rue du Dr Roux, 75724 Paris, Cedex 15, France. Phone: 33-1-45 6884 46. Fax: 33-1-40 613583 (e-mail: stcole@ pasteur.fr) 
needed, the future of leprosy treatment is well poised. Nevertheless, it is important not to neglect any opportunities for improvement and to remain aware of potential new leads for strengthening the chemotherapy of leprosy.

Drug resistance in bacteria can result from four different mechanisms. The commonest one, found in bacteria, is the enzymatic inactivation of the antibiotic by modification or hydrolysis. Since the genes encoding these enzymes are generally transferable, this resistance mechanism has often limited the usefulness of numerous $\beta$-lactam and aminoglycoside compounds. Transferable drug resistance has not been reported among the intracellular mycobacteria where the most frequent mechanism encountered is alteration of the drug target by mutation, ${ }^{9,10}$ which is the case for rifampicin resistance in Mycobacterium leprae ${ }^{11,12}$ In some pathogens, innate drug resistance results from efficient permeability barriers preventing the entry of sufficient concentrations of drugs into the cell, and this appears to be operational in some mycobacteria. ${ }^{13,14}$ Active efflux of antibiotics also occurs from various pathogens, including mycobacteria, ${ }^{15}$ and is mediated by protein pumps that belong to different families such as the major facilitator superfamily (MFS), the resistance-nodulation-division (RND) superfamily, the ATP-binding cassette $(\mathrm{ABC})$ superfamily, or the small multidrug resistance (SMR) superfamily. ${ }^{16-18}$

The genome sequence of $M$. leprae ${ }^{19}$ provides clear explanations for the natural resistance of the leprosy bacillus to many antitubercular compounds and also indicates areas of potential susceptibility where existing drugs might find application. Our aim here is to discuss these topics in the light of the available clinical and microbiological knowledge.

\section{Materials and methods}

Bioinformatic analysis was performed using the procedures outlined previously ${ }^{19,20}$ in conjunction with the relational databases, Leproma (http://genolist.pasteur.fr/Leproma/ ${ }^{21}$ ) and TubercuList (http://genolist.pasteur.fr/TubercuList/).

\section{Results and discussion}

RIFAMPICIN, DAPSONE AND CLOFAZIMINE

WHO-recommended MDT relies on the association of three agents: rifampicin, dapsone and clofazimine. Since rifampicin is the backbone of leprosy treatment, the genome sequencing project began by studying the region encompassing the $r p o B$ gene, encoding the drug target, the $\beta$-subunit of DNA-dependent RNA polymerase. ${ }^{22}$ The sequence information, in conjunction with a panel of well-characterized resistant patient isolates, ${ }^{23}$ enabled the molecular basis of rifampicin resistance to be elucidated. ${ }^{11}$ Missense mutations were found in a restricted region of $r p o B$ that probably reduces the affinity of the drug for RNA polymerase, and this information has been used to develop rapid diagnostic tests for resistance. ${ }^{12,24,25}$ There is only one $r p o B$ and no other genes associated with rifampicin resistance, like those mediating its ribosylative inactivation in certain actinomycetes, ${ }^{26,27}$ could be found in the genome. This explains why other rifamycin derivatives that have the same drug target as rifampicin are inactive because of cross-resistance, and cannot be used as replacement drugs in the case of rifampicin resistance. However, some of them have pharmacokinetic 
parameters more favourable than those of rifampicin for monthly administration. For example, rifapentine, a long lasting rifamycin derivative, has a serum half life 6 times longer than that of rifampicin and gives in humans an AUC after oral administration of $600 \mathrm{mg}$, 3 times larger than that given by $600 \mathrm{mg}$ of rifampicin. Consequently, a monthly regimen containing rifapentine combined with a new fluoroquinolone and minocycline is under intensive investigation at the present time. ${ }^{67}$

Possibly as a result of its widespread, initial use in monotherapy, primary resistance to dapsone became common in the 1960s. Again, genomics was of great importance for understanding the basis of this resistance as the availability of the folate synthase gene sequence, folP1, enabled Kai and coworkers to demonstrate the presence of mutations in the gene from dapsone resistant strains. ${ }^{28}$ Intriguingly, both Mycobacterium tuberculosis and $M$. leprae have a second gene, folP2, that resembles folP1, but this does not encode folate synthase nor mediate dapsone sensitivity. ${ }^{29}$ Since folate synthesis is an essential activity, missense mutations occur that lead to amino acid substitutions at positions 53 and $55,{ }^{28,29}$ and from the crystal structure of the $M$. tuberculosis enzyme it is apparent that these are located in loop 2 near the active site. ${ }^{30}$ The availability of the three-dimensional structure will allow lead compounds for antimycobacterial drug design to be designed in a rational manner, and clearly, if successful, this could benefit leprosy treatment.

The third component of MDT, clofazimine, is the least well understood in terms of its mode of action and resistance mechanism. ${ }^{31}$ Its activity is primarily confined to mycobacteria where it is believed to bind to DNA. The genome sequence has yet to provide clues to possible targets.

ISONIAZID, ETHIONAMIDE, CELL WALL INHIBITORS

The unusual cell wall of mycobacteria has provided a rich and specific source of drug targets and, with the exception of rifampicin, three of the four agents used in the short course chemotherapy of tuberculosis block the synthesis of cell wall components. Somewhat surprisingly, in light of the conserved, if somewhat simplified nature of the cell wall of M. leprae, ${ }^{32}$ none of these compounds is active, but explanations for their lack of efficacy are provided by the genome sequence. Isoniazid (INH) is exquisitely potent on the tubercle bacillus, where it is converted by catalase-peroxidase, ${ }^{33}$ to an iso-nicotinoyl radical ${ }^{34}$ which forms an adduct with NADH that blocks the action of the enoyl-ACP reductase, InhA. ${ }^{35,36}$ This enzyme is involved in mycolic acid synthesis, as part of the fatty acid synthase II complex (FAS II), and is also a target for ethionamide. ${ }^{35}$ In addition, INH interacts directly with another FAS II component, the beta-ketoacyl-ACP synthase, KasA. ${ }^{37,38}$

Although $M$. leprae has an intact FAS II system and functional kasA and inhA genes, it is not susceptible to clinically significant levels of INH as a result of multiple lesions in the catalase-peroxidase $(k a t G)$ gene. ${ }^{39,40}$ Unlike some other mycobacteria, ${ }^{41}$ the genome of $M$. leprae does not contain a second catalase-peroxidase gene. ${ }^{19}$ By contrast, as the FAS II complex is active, it is possible that $M$. leprae will be susceptible to triclosan, which inhibits InhA, and to an old compound, thiolactomycin, which affects KasA in M. tuberculosis, and other bacteria. ${ }^{38}$ The leprosy bacillus is known to be inhibited by prothionamide (combined with isoniazid and dapsone in the fixed drug combination isoprodian), a hepatoxic drug ${ }^{42}$ which, like ethionamide, should target InhA. It has recently been shown that ethionamide requires an activation step that is catalysed by a monooxygenase belonging to a 14-membered family (http://genolist.pasteur.fr/TubercuList/mast/ 
P14.2.html) in M. tuberculosis. ${ }^{43,44}$ It is of some interest that expression of the monooxygenase gene, Rv3854c, (ethA or etaA) is regulated by a TetR repressor protein encoded by the neighbouring gene Rv3855, (ethR, etaR). Both the monoxygenase and the regulatory gene have been conserved in M. leprae, (ML0064, ML0065), implying that thioamide activation should proceed in a similar manner. Astonishingly, the monoxygenase gene is the sole survivor of the P14.2 family and, in the face of such extensive gene loss, ${ }^{19}$ this implies that its physiological function must be important for M. leprae in particular, and mycobacteria in general.

Ethambutol inhibits the arabinosyltransferase(s), membrane-bound enzymes involved in the polymerization of arabinan which, in turn, impacts on arabinogalactan and lipoarabinomannan production thereby destabilizing the cell wall. ${ }^{45}$ Using complementary approaches with $M$. tuberculosis and Mycobacterium avium, ${ }^{46,47}$ these enzymes were shown to be encoded by linked genes, $e m b(C) A B$, that have evolved by a gene duplication mechanism and are probably controlled by the regulatory gene, embR. While $M$. leprae has the embCAB operon it appears to have lost $e m b R$, which may mean that arabinosyltransferase production is no longer regulated. ${ }^{19}$ Missense mutations located in a tetrapeptide at positions 303-306 of EmbB are responsible for acquired drug resistance in the majority of clinical isolates of M. tuberculosi ${ }^{48}$ and in laboratory mutants of Mycobacterium smegmatis. ${ }^{49}$ The embB gene of $M$. leprae harbours a 'mutation' at this position ${ }^{46}$ and this undoubtedly accounts for its natural resistance to ethambutol.

Pyrazinamide is the third antitubercular agent that is believed to affect cell wall biogenesis possibly through indirect effects on fatty acid synthesis mediated by FAS I in the tubercle bacillus. ${ }^{50}$ Drug activity requires its conversion to pyrazinoic acid in a reaction catalysed by the pyrazinamidase enzyme encoded by pncA in $M$. tuberculosis ${ }^{51}$ or by a broadspectrum amidase coded for by pzaA in M. smegmatis. ${ }^{52,53}$ Resistance is associated with mutations that inactivate $p n c A$, or alter the stability of pyrazinamidase, and in some mycobacteria, pyrazinoic acid efflux systems may also contribute. ${ }^{54,55}$ The pncA gene of $M$. leprae has been inactivated and the genome contains no counterpart of $p z a A$. Pyrazinamide is therefore likely to be of no therapeutic value for leprosy.

\section{TRANSLATION INHIBITORS}

Antibiotics belonging to the tetracyline, aminoglycoside and macrolide families are potent inhibitors of protein synthesis. The aminoglycosides streptomycin and kanamycin show strong bactericidal activity in the mouse, and streptomycin has been used to treat leprosy in humans. ${ }^{56}$ Resistance to streptomycin in mycobacteria arises as a result of missense mutations to the rpsL and rrs genes encoding the drug targets, the ribosomal protein S12 and the $16 \mathrm{~S}$ rRNA, respectively. ${ }^{57,58}$ Likewise, resistance to kanamycin is due to base changes around position 1400 in the $16 \mathrm{~S}$ rRNA of $M$. tuberculosis that prevent the drug from binding. ${ }^{59}$ As expected, both genes have wild type sequences in $M$. leprae thereby explaining its susceptibility to streptomycin and kanamycin.

Clarithromycin is a macrolide antibiotic that shows bactericidal activity against M. leprae in mice and humans. ${ }^{5,6}$ Susceptibility can be attributed to the wild type sequence of the $r r l$ gene, encoding the 23S rRNA. A to G transitions affecting positions 2058 and 2059 of this RNA have been described in clarithromycin resistant strains of $M$. avium and Mycobacterium kansasii, among others. ${ }^{60,61}$ Minocycline, a second-generation tetracycline, is also active on M. leprae ${ }^{7,62}$ probably as a result of its ability to bind to a site on the ribosome comprising 
proteins S7, S14, S19 and the $3^{\prime}$ domain of 16 S rRNA. At present nothing is known about minocycline resistance in mycobacteria, although tetracycline resistance has been studied intensively in other Gram positive bacteria where it often involves efflux or ribosome protection systems ${ }^{63}$

Fusidic acid is another broad spectrum antibiotic that targets the ribosome and inhibits the growth of $M$. leprae. ${ }^{64,65}$ It acts by preventing release of elongation factor EF-G from the ribosome and, in enteric bacteria, fusidic acid resistance is due to missense mutations in three highly conserved regions of the $e f g$ gene. ${ }^{66}$ The availablity of the efg sequence of $M$. leprae allows genotypic tests for resistance to be developed should the need arise. ${ }^{22}$

\section{QUINOLONES}

Fluoroquinolones offer great potential to the future therapy of leprosy and have shown outstanding activity in vitro and in vivo. ${ }^{4,62,67}$ Ofloxacin is a key component of the ROM regimen, discussed above, although some of the newer fluoroquinolones such as moxifloxacin appear to be even more bactericidal. A limited number of cases of fluoroquinolone resistance have been reported $^{68}$ and, as in M. tuberculosis, ${ }^{69}$ these involve amino acid substitutions in the quinolone resistance determining region, QRDR, of the DNA gyrase A protein. In some bacteria, resistance also results from alterations of DNA topoisomerase IV, but genomics suggests that both M. leprae and M. tuberculosis lack this function. ${ }^{19,70}$ The QRDR is situated very near the active site of GyrA and most unusually this region of gyrA has acquired an intein sequence coding for a putative homing endonuclease. ${ }^{71}$ In consequence, production of active GyrA requires excision of the intein from the nascent polypeptide by protein splicing. There are three other inteins in the ML0593, dnaB, and recA genes of $M$. leprae, although these all differ in size and sequence. ${ }^{72}$ Since both gyr $A$ and $d n a B$ encode essential functions they are valid drug targets whose functions would be lost if protein splicing were blocked.

\section{ANTIBIOTIC INACTIVATION}

Of the several reasons why $M$. leprae shows susceptibility to a broader range of drugs than $M$. tuberculosis, one is provided by the finding that its genome contains far fewer genes encoding enzymes that could inactivate or modify antibiotics. Only two of the 10 genes, annotated as being putatively involved in antibiotic modification in M. tuberculosis, are predicted to be functional in M. leprae. One of these, ML2551, encodes an aminoglycoside$2^{\prime}$-N-acetyltransferase that may be involved in peptidoglycan modification. ${ }^{73}$

While the tubercle bacillus has seven known or potential $\beta$-lactamase genes (Table 1 ), M. leprae has only two that appear to be functional (ML0270, ML1923). Consequently, $\beta$-lactam antibiotics may be more active in leprosy than in tuberculosis. It should be noted that there is no blaC ortholog encoding the class-A $\beta$-lactamase present in $M$. tuberculosis which contributes to its innate resistance to $\beta$-lactam antibiotics. ${ }^{74,75}$ As expected of a classA enzyme, inhibition was achieved by the $\beta$-lactamase inhibitors clavulanate or sulbactam, thereby raising the possibility of treating tuberculosis with penicillins and cephalosporins in conjunction with such inhibitors. There has been some recent interest in using these combinations to treat leprosy as well, inspired in part by Shephard's observations that, of the $12 \beta$-lactams tested, two cephalosporins and one cephamycin were active in the mouse 
Table 1. Predicted $\beta$-lactamase-like proteins in tubercle and leprosy bacilli

\begin{tabular}{lll}
\hline Gene & \multicolumn{1}{c}{ Predicted function in M. tuberculosis } & M. leprae* \\
\hline blaC $(\mathrm{Rv} 2068 \mathrm{c})$ & Class A $\beta$-lactamase & del \\
lipD $(\mathrm{Rv} 1923)$ & Similar to esterases, $\beta$-lactamase & del \\
$l p p W(\mathrm{Rv} 2905)$ & Lipoprotein with slight similarity to $\beta$-lactamase & ML1614, ps \\
$l p q F(\mathrm{Rv} 3593)$ & Lipoprotein with slight similarity to class C $\beta$-lactamase & ML1923 \\
Rv0406c & $\beta$-lactamase-like protein with Pfam match PF00753 & ML0270 \\
& lactamase_B, metallo-beta-lactamase superfamily & \\
Rv0907 & Similar to PBP 4, class C $\beta$-lactamase & ML2116, ps \\
Rv1913 & Similar to dehydrase, metallo- $\beta$-lactamase & ML2001, ps \\
& & \\
\hline
\end{tabular}

*ps, denotes pseudogene; del, missing probably deleted.

footpad model. ${ }^{76}$ In two studies involving $\beta$-lactam antibiotics with $\beta$-lactamase inhibitors, bactericidal activity was reported. ${ }^{77,78}$.

\section{DRUG EFFLUX}

Another potential mechanism that could contribute to natural antimicrobial resistance is drug efflux and, in some pathogenic bacteria, this is known to be mediated by transmembrane proteins belonging to the ATP-binding cassette (ABC), and major facilitator superfamilies (MFS), ${ }^{16}$ the small multidrug resistance family (SMR) and the resistance/nodulation/cell division family (RND). ${ }^{17,18,79} \mathrm{M}$. le prae has proteins belonging to all four of these families but they are considerably less abundant than in the tubercle bacillus.

Careful analysis of the ABC transport proteins of $M$. tuberculosis has been undertaken, ${ }^{80}$ and these can be divided into import and export systems on the basis of their structure and organization. Of the 11 potential drug export systems predicted (Table 2), only six remain in M. leprae. Pseudogenes for two may be found and the remainder appear to have been deleted. The $d r r A B C$ system is very similar to those produced by various Streptomyces spp. and like them may also be involved in the export of daunorubicin-like molecules. ${ }^{81}$ Investigations into the possible contribution of some of the $\sim 30$ MFS proteins of M. tuberculosis to drug efflux have been reported and these can be used to interpret the likely role of the few remaining orthologs in M. leprae. Two MFS proteins, Rv1258c and Rv1410c, have been shown to serve as proton motive force-dependent drug pumps that confer increased resistance to several aminoglycosides and tetracycline when expressed in M. smegmatis, ${ }^{82,83}$ Both of these functions have been conserved in $M$. leprae, together with a third MFS protein, EfpA (Table 2) which is similar to the multidrug resistance pump, QacA. ${ }^{84}$ Recently, expression of EfpA has been shown to be strongly induced during drug-mediated inhibition of cell wall synthesis in $M$. tuberculosis. ${ }^{85}$ It is possible that these three conserved MFS proteins also act as drug pumps in M. leprae (Table 2).

$M$. leprae, like the tubercle bacillus, has only one member of the SMR family, the 108 residue ML1756 protein (Table 2, equivalent to Rv3065) and this has four transmembrane stretches like its relatives. ${ }^{19,70}$ When expressed in M. smegmatis the Rv3065gene confers resistance to a variety of compounds, including acriflavine, erythromycin, ethidium bromide, safranin $\mathrm{O}$, and pyronin Y 8586. M. tuberculosis is somewhat unusual as its genome contains 16 genes (Table 2) encoding members of the RND superfamily, ${ }^{79}$ an exceptionally high 
Table 2. Predicted drug efflux systems in tubercle and leprosy bacilli

\begin{tabular}{lll} 
ABC systems & & \\
Gene & Predicted function in $M$. tuberculosis & M. leprae* \\
\hline$d r r A B C$ & Daunorubicin resistance & drrABC \\
Rv1456-58c & Antibiotic resistance & ML0590, ML0589 \\
Rv2686-88c & Antibiotic resistance & ML1033-35, ps \\
Rv1217-18c & Antibiotic resistance & ML1072-73, ps \\
Rv1272-73c & Multidrug resistance & ML1113-14 \\
Rv1348-49 & Multidrug resistance & del \\
Rv0194 & Multidrug resistance & del \\
Rv1819c & Multidrug resistance & ML2084 \\
Rv1473 & Macrolide resistance & ML1816 \\
Rv2477c & Macrolide resistance & ML1248 \\
Rv1667-68c & Macrolide resistance & ML1239-40, ps \\
\hline
\end{tabular}

\section{MFS systems}

\begin{tabular}{lll} 
Gene & Observed or predicted function in M. tuberculosis & M. leprae \\
\hline tap (Rv1258c) & Aminoglycoside, tetracycline efflux & ML1104 \\
efpA (Rv2846c) & Induced by drugs & ML1562 \\
Rv1410c & P55, aminoglycoside, tetracycline efflux & ML0556 \\
Rv1877, Rv2044, Rv2333c & Probable drug efflux proteins & All missing \\
Rv2459, Rv3728, Rv3239c & Probable drug efflux proteins & All missing \\
\hline
\end{tabular}

\section{SMR systems}

\begin{tabular}{|c|c|c|}
\hline Gene & Predicted function in $M$. tuberculosis & M. leprae \\
\hline emrE (Rv3065) & $\begin{array}{l}\text { Acriflavine, erythromycin, ethidium bromide, } \\
\text { safranin } \mathrm{O} \text {, pyronin Y resistance }\end{array}$ & ML1756 \\
\hline \multicolumn{3}{|l|}{ RND systems } \\
\hline Gene & Known or predicted function in $M$. tuberculosis & M. leprae \\
\hline$m m p L 1-6$ & Lipid transport & $\begin{array}{l}\text { mmpL3 (ML2620) } \\
m m p L A(\text { ML2378) }\end{array}$ \\
\hline$m m p L 7$ & PDIM transport & mmpL7 (ML0137) \\
\hline$m m p L 8-14$ & lipid transport & $\begin{array}{l}\text { mmpL10 (ML1231) } \\
\text { mmp11 (ML2617) }\end{array}$ \\
\hline
\end{tabular}

ps, denotes pseudogene; del, missing probably deleted.

number compared to other fully sequenced bacterial genomes rivalled only by Pseudomonas aeruginosa. ${ }^{87}$ There are only five RND proteins predicted in M. leprae (Table 2).

In the Gram negative pathogens $P$. aeruginosa and Escherichia coli, RND proteins, such as $\mathrm{MexAB}$ or $\mathrm{Acr} \mathrm{AB}$ ( $\sim 1000$ amino acids), act as proton motive force-dependent efflux systems and confer high levels of resistance to fluoroquinolones and other antimicrobial agents. ${ }^{88,89}$ The genetic context of the $m m p L$ genes, encoding the $M$. tuberculosis RND proteins, suggested an involvement in the export of lipids or glycolipids, and a body of experimental evidence to support this has since been amassed. ${ }^{90,91}$ In particular, the MmpL7 protein is responsible for the export of the complex lipid phthiocerol-dimycocerosate (PDIM) and in M. leprae, modifies PDIM to produce phenolic glycolipid 1 (PGL1), MmpL7 may be 
involved in the transport of PGL1. Given the similarities with other RND transporters it is possible that the MmpL proteins can also act in drug efflux, and as $M$. leprae produces far fewer than the tubercle bacillus does, it should be susceptible to more drugs as has been observed.

\section{NEW DRUG REGIMENS AND NEW LEADS FOR DRUG DISCOVERY}

Given the cost of developing new drugs, it seems certain that the pharmaceutical industry will not invest in the field of leprosy although tuberculosis may present a somewhat more lucrative market. Consequently, pharmacogenomics and high-throughput screening technologies will not be applied directly to $M$. leprae and we must look elsewhere for new leads for drug discovery. An exciting opening has emerged recently from studying the action of nitroimidazopyran derivatives on $M$. tuberculosis and a novel compound, PA824, shows great promise. $^{92}$ In order to be active, PA824 requires the F420-dependent glucose-6-phosphate dehydrogenase encoded by $f g d$, (Rv0407), and resistance mutations reside in this gene which is also conserved in M. leprae (ML0269). It is thus conceivable that PA824 could find use in leprosy treatment and a particularly attractive feature of this drug is its action under microaerophilic growth conditions similar to those which M. leprae is believed to favour. ${ }^{19}$

Another area where novel drug targets may be found is in signal transduction. In most bacteria, changes in gene expression in response to environmental cues are mediated by the His-Asp phosphorelay system effected by the two-component systems. ${ }^{93}$ These are common in prokaryotes and comprise a membrane-bound sensor protein with histidine kinase activity which phosphorylates an aspartyl residue in a response regulator protein that in turn controls the target genes. In mycobacteria, a second, eukaryotic like phosphorelay system may be found in the form of the serine-threonine protein kinases and their cognate phosphoprotein phosphatases and these may also control cellular processes such as division and septation. $^{70,94}$ The pharmaceutical industry has batteries of lead compounds for both of these protein kinase families, since there has been intensive research into the histidine kinases as novel drug targets in recent years, ${ }^{95,96}$ and numerous inhibitors of serine threonine protein kinases have been developed for use in cancer treatment. If these kinase inhibitors became available, they should certainly be tested on $M$. leprae as this pathogen has only four complete two-component systems and four serine-threonine protein kinases, thus increasing the chances of attaining complete inhibition.

\section{Acknowledgements}

We wish to acknowledge the financial support of the Institut Pasteur, the Association Française Raoul Follereau, and the European Community (QLRT-2000-02018).

\section{References}

I WHO Study Group. Chemotherapy of leprosy for control programmes. Technical Report Series No. 675. World Health Organization, Geneva, Switzerland, 1982.

2 WHO Leprosy - Global Situation. Weekly Epidemiological Record, 2000; No. 28, 14 July.

${ }^{3}$ Snider DE Jr, Raviglione M, Kochi A. Global burden of tuberculosis. In: Bloom BR (ed) Tuberculosis: pathogenesis, protection, and control. American Society for Microbiology, Washington DC 20005, 1994. 
4 Consigny S, Bentoucha A, Bonnafous P et al. Bactericidal activities of HMR 3647, moxifloxacin, and rifapentine against Mycobacterium leprae in mice. Antimicrob Agents Chemother, 2000; 44: 2919-2921.

5 Ji B, Jamet P, Perani EG et al. Bactericidal activity of single dose of clarithromycin plus minocycline, with or without ofloxacin, against Mycobacterium leprae in patients. Antimicrob Agents Chemother, 1996; 40: 2137 2141.

6 Ji B, Perani EG, Petinom C, Grosset JH. Bactericidal activities of combinations of new drugs against Mycobacterium leprae in nude mice. Antimicrob Agents Chemother, 1996; 40: 393-399.

7 Ji B, Sow S, Perani E et al. Bactericidal activity of a single-dose combination of ofloxacin plus minocycline, with or without rifampin, against Mycobacterium leprae in mice and in lepromatous patients. Antimicrob Agents Chemother, 1998; 42: 1115-1120.

${ }^{8}$ Efficacy of single dose multidrug therapy for the treatment of single-lesion paucibacillary leprosy. Single-lesion Multicentre Trial Group. Ind J Lepr, 1997; 69: 121.

9 Cole ST. Mycobacterium tuberculosis: drug resistance mechanisms. Trends Microbiol, 1994; 2: 411-415.

${ }^{10}$ Ramaswamy S, Musser JM. Molecular genetic basis of antimicrobial agent resistance in Mycobacterium tuberculosis: 1998 update. Tuberc Lung Dis, 1998; 79: 3-29.

11 Honoré N, Cole ST. Molecular basis of rifampin-resistance in Mycobacterium leprae. Antimicrob Agents Chemother, 1993; 37: 414-418.

12 Williams DL, Waguespack C, Eisenach $\mathrm{K}$ et al. Characterization of rifampin resistance in pathogenic mycobacteria. Antimicrob Agents Chemother, 1994; 38: 2380-2386.

13 Brennan PJ, Nikaido H. The envelope of mycobacteria. Annu Rev Biochem, 1995; 64: 29-63.

14 Jarlier V, Nikaido H. Permeability barrier to hydrophilic solutes in Mycobacterium chelonei. J Bacteriol, 1990; 172: $1418-1423$.

${ }^{15}$ Liu J, Takiff HE, Nikaido H. Active efflux of fluoroquinolones in Mycobacterium smegmatis mediated by LfrA, a multidrug efflux pump. J Bacteriol, 1996; 178: 3791-3795.

16 Pao SS, Paulsen IT, Saier MJ. Major facilitator superfamily. Microbiol Mol Biol Rev, 1998; $62:$ 1-34.

17 Paulsen IT, Brown MH, Skurray RA. Proton-dependent multidrug efflux systems. Microbiol. Rev, 1996; 60: 575608.

18 Paulsen IT, Sliwinski MK, Saier MJ. Microbial genome analyses: global comparisons of transport capabilities based on phylogenies, bioenergetics and substrate specificities. J Mol Biol, 1998; 277: 573-592.

${ }^{19}$ Cole ST, Eiglmeier K, Parkhill J et al. Massive gene decay in the leprosy bacillus. Nature, 2001; 409: 1007-1011.

20 Tekaia F, Gordon SV, Garnier T et al. Analysis of the proteome of Mycobacterium tuberculosis in silico. Tuberc Lung Dis, 1999; 79: 329-342.

21 Jones LM, Cole ST, Moszer I. Leproma: a Mycobacterium le prae genome browser. Lepr Rev, 2001; 72: $429-440$.

${ }^{22}$ Honoré N, Bergh S, Chanteau S et al. Nucleotide sequence of the first cosmid from the Mycobacterium leprae genome project: structure and function of the Rif-Str regions. Mol Microbiol, 1993; 7: 207-214.

23 Grosset JH, Guelpa-Lauras CC, Bobin P et al. Study of 39 documented relapses of multibacillary leprosy after treatment with rifampin. Int J Lepr, 1989; 57: 607-614.

${ }^{24}$ Honoré N, Perani E, Telenti A et al. A simple and rapid technique for the detection of rifampin resistance in Mycobacterium leprae. Int J Lepr, 1994; 61: 600-604.

${ }^{25}$ Honoré N, Roche P, Grosset J, Cole ST. A method for rapid detection of rifampicin-resistant isolates of Mycobacterium leprae. Lepr Rev, 2001; 72: 441-448.

26 Quan S, Venter H, Dabbs ER. Ribosylative inactivation of rifampin by Mycobacterium smegmatis is a principal contributor to its low susceptibility to this antibiotic. Antimicrob Agents Chemother, 1997; 41: 2456-2460.

27 Andersen SJ, Quan S, Gowan B, Dabbs ER. Monooxygenase-like sequence of a Rhodococcus equi gene conferring increased resistance to rifampin by inactivating this antibiotic. Antimicrob Agents Chemother, 1997; 41: $218-221$.

${ }^{28}$ Kai M, Matsuoka M, Nakata N et al. Diaminodiphenylsulfone resistance of Mycobacterium leprae due to mutations in the dihydropteroate synthase gene. FEMS Microbiol Lett, 1999; 177: 231-235.

29 Williams DL, Spring L, Harris E et al. Dihydropteroate synthase of Mycobacterium leprae and dapsone resistance. Antimicrob Agents Chemother, 2000; 44: 1530-1537.

30 Baca AM, Sirawaraporn R, Turley S et al. Crystal structure of Mycobacterium tuberculosis 7,8-dihydropteroate synthase in complex with pterin monophosphate: new insight into the enzymatic mechanism and sulfa-drug action. J Mol Biol, 2000; 302: 1193-1212.

31 Chopra I, Brennan P. Molecular action of anti-mycobacterial agents. Tuberc Lung Dis, 1997; 78: 89-98.

32 Brennan PJ, Vissa VD. Genomic evidence for the retention of the essential mycobacterial cell wall in the otherwise defective Mycobacterium leprae. Lepr Rev, 2001; 72: 415-428.

33 Zhang Y, Heym B, Allen B et al. The catalase-peroxidase gene and isoniazid resistance of Mycobacterium tuberculosis. Nature, 1992; 358: 591-593.

34 Johnsson K, Schultz PG. Mechanistic studies of the oxidation of isoniazid by the catalase-peroxidase from Mycobacterium tuberculosis. J Am Chem Soc, 1994; 116: 7425-7426.

35 Banerjee A, Dubnau E, Quémard A et al. inhA, a gene encoding a target for isoniazid and ethionamide in Mycobacterium tuberculosis. Science, 1994; 263: 227-230. 
${ }^{36}$ Rozwarski DA, Grant GA, Barton DHR et al. Modification of the NADH of the isoniazid target (InhA) from Mycobacterium tuberculosis. Science, 1998; 279: 98-102.

37 Slayden RA, Barry CE 3rd. The genetics and biochemistry of isoniazid resistance in mycobacterium tuberculosis. Microbes Infect, 2000; 2: 659-669.

38 Slayden RA, Lee RE, Barry CE 3rd. Isoniazid affects multiple components of the type II fatty acid synthase system of Mycobacterium tuberculosis. Mol Microbiol, 2000; 38: 514-525.

39 Eiglmeier K, Fsihi H, Heym B, Cole ST. On the catalase-peroxidase gene, katG, of Mycobacterium leprae and the implications for treatment of leprosy with isoniazid. FEMS Microbiol Lett, 1997; 149: 273-278.

${ }^{40}$ Nakata N, Matsuoka M, Kashiwabara Y et al. Nucleotide sequence of the Mycobacterium leprae katG region. $J$ Bacteriol, 1997; 179: 3053-3057.

41 Menendez MC, Ainsa JA, Martin C, Garcia MJ. katGI and katGII encode two different catalases-peroxidases in Mycobacteriurn fortuitum. J Bacteriol, 1997; 179: 6880-6886.

42 Cartel JL, Millan J, Guelpa-Lauras CC, Grosset JH. Hepatitis in leprosy patients treated by a daily combination of dapsone, rifampin, and a thioamide. Int J Lepr Other Mycobact Dis, 1983; 51: 461-465.

43 DeBarber AE, Mdluli K, Bosman $\mathbf{M}$ et al. Ethionamide activation and sensitivity in multidrug-resistant Mycobacterium tuberculosis. Proc Natl Acad Sci USA, 2000; 97: 9677-9682.

44 Baulard AR, Betts JC, Engohang-Ndong J et al. Activation of the pro-drug ethionamide is regulated in mycobacteria. J Biol Chem, 2000; 275: 28326-28331.

45 Khoo KH, Douglas E, Azadi P et al. Truncated structural variants of lipoarabinomannan in ethambutol drugresistant strains of Mycobacterium smegmatis. Inhibition of arabinan biosynthesis by ethambutol. $\mathrm{J}$ Biol Chem, 1996; 271: 28682-28690.

46 Telenti A, Philipp WJ, Sreevatsan S et al. The emb operon, a gene cluster of Mycobacterium tuberculosis involved in resistance to ethambutol. Nature Med, 1997; 3: 567-570.

47 Belanger AE, Besra GS, Ford ME et al. The embAB genes of Mycobacterium avium encode an arabinosyl transferase involved in cell wall arabinan biosynthesis that is the target for the antimycobacterial drug ethambutol. Proc Natl Acad Sci USA, 1996; 93: 11919-11924.

48 Sreevatsan S, Stockbauer KE, Pan X et al. Ethambutol resistance in Mycobacterium tuberculosis: critical role of embB mutations. Antimicrob Agents Chemother, 1997; 41: 1677-1681.

49 Lety MA, Nair S, Berche P, Escuyer V. A single point mutation in the embB gene is responsible for resistance to ethambutol in Mycobacterium smegmatis. Antimicrob Agents Chemother, 1997; 41: 2629-2633.

50 Zimhony O, Cox JS, Welch JT et al. Pyrazinamide inhibits the eukaryotic-like fatty acid synthetase I (FASI) of Mycobacterium tuberculosis. Nature Med, 2000; 6: 1043-1047.

51 Scorpio A, Zhang Y. Mutations in pncA, a gene encoding pyrazinamidase/nicotinamidase, cause resistance to the antituberculous drug pyrazinamide in tubercle bacillus. Nature Med, 1996; 2: 662-667.

52 Boshoff HI, Mizrahi V. Purification, gene cloning, targeted knockout, overexpression, and biochemical characterization of the major pyrazinamidase from Mycobacterium smegmatis. J Bacteriol, 1998; 180: 58095814.

53 Boshoff HI, Mizrahi V. Expression of Mycobacterium smegmatis pyrazinamidase in Mycobacterium tuberculosis confers hypersensitivity to pyrazinamide and related amides. J Bacteriol, 2000; 182: 5479-5485.

54 Zhang Y, Scorpio A, Nikaido H, Sun Z. Role of acid pH and deficient efflux of pyrazinoic acid in unique susceptibility of Mycobacterium tuberculosis to pyrazinamide. J Bacteriol, 1999; 181: 2044-2049.

55 Pym AS, Cole ST. Tuberculosis chemotherapy - from conception to genomics. In: Wax R, Lewis K, Salyers A, Taber H (eds) Bacterial resistance to antimicrobials: mechanisms, genetics, medical practice and public health. Marcel Dekker, New York, 2001, pp. 355-403.

56 Gelber RH. Further studies of the killing of M. leprae by aminoglycosides: reduced dosage and frequency of administration. Int J Lepr Other Mycobact Dis, 1987; 55: 78-82.

57 Honoré N, Cole ST. Streptomycin and mycobacteria. Antimicrob Agents Chemother, 1994; 38: 238-242.

58 Meier A, Kirschner P, Bange F-C et al. Genetic alterations in streptomycin-resistant Mycobacterium tuberculosis: Mapping of mutations conferring resistance. Antimicrob Agents Chemother, 1994; 38: 228-233.

59 Suzuki Y, Katsukawa C, Tamaru A et al. Detection of kanamycin-resistant Mycobacterium tuberculosis by identifying mutations in the 16S rRNA gene. J Clin Microbiol, 1998; 36: 1220-1225.

60 Burman WJ, Stone BL, Brown BA et al. AIDS-related Mycobacterium kansasii infection with initial resistance to clarithromycin. Diagn Microbiol Infect Dis, 1998; 31: 369-371.

${ }^{61}$ Meier A, Heifets L, Wallace RJ Jr et al. Molecular mechanisms of clarithromycin resistance in Mycobacterium avium: observation of multiple $23 \mathrm{~S}$ rDNA mutations in a clonal population. $J$ Infect Dis, 1996; 174: $354-360$.

$62 \mathrm{Ji} \mathrm{B}$, Perani EG, Petinom C, Grosset JH. Bactericidal activities of combinations of new drugs against Mycobacterium leprae in nude mice. Antimicrob Agents Chemother, 1996; 40: 2137-2141.

63 Speer BS, Shoemaker NB, Salyers AA. Bacterial resistance to tetracycline: mechanisms, transfer, and clinical significance. Clin Microbiol Rev, 1992; 5: 387-399.

64 Franzblau SG, Chan GP, Garcia-Ignacio BG et al. Clinical trial of fusidic acid for lepromatous leprosy. Antimicrob Agents Chemother, 1994; 38: 1651-1654. 
${ }^{65}$ Franzblau SG, Biswas AN, Harris EB. Fusidic acid is highly active against extracellular and intracellular Mycobacterium leprae. Antimicrob Agents Chemother, 1992; 36: 92-94.

66 Johanson U, Hughes D. Fusidic acid-resistant mutants define three regions in elongation factor G of Salmonella typhimurium. Gene, 1994; 143: 55-59.

$67 \mathrm{Ji} \mathrm{B}$, Grosset J. Combination of rifapentine-moxifloxacin-minocycline (PMM) for the treatment of leprosy. Lepr Rev, 2000; 71: S81-87.

68 Cambau E, Perani E, Guillemin I et al. Multidrug-resistance to dapsone, rifampicin, and ofloxacin in Mycobacterium leprae. Lancet, 1997; 349: 103-104.

69 Takiff HE, Salazar L, Guerrero C et al. Cloning and nucleotide sequence of the Mycobacterium tuberculosis gyrA and gyrB genes, and characterization of quinolone resistance mutations. Antimicrob Agents Chemother, 1994; 38: 773-780.

70 Cole ST, Brosch R, Parkhill J et al. Deciphering the biology of Mycobacterium tuberculosis from the complete genome sequence. Nature, 1998; 393: 537-544.

71 Fsihi H, Vincent V, Cole ST. Homing events in the gyrA gene of some mycobacteria. Proc Natl Acad Sci USA, 1996; 93: 3410-3415.

72 Davis EO, Thangaraj HS, Brooks PC, Colston JM. Evidence of selection for protein introns in the RecAs of pathogenic mycobacteria. EMBO J, 1994; 13: 699-703.

73 Ainsa JA, Perez E, Pelicic V et al. Aminoglycoside 2'-N-acetyltransferase genes are universally present in mycobacteria: characterization of the aac(2')-Ic gene from Mycobacterium tuberculosis and the aac(2')-Id gene from Mycobacterium smegmatis. Mol Microbiol, 1997; 24: 431-441.

74 Chambers HF, Moreau D, Yajko D et al. Can penicillins and other beta-lactam antibiotics be used to treat tuberculosis? Antimicrob Agents Chemother, 1995; 39: 2620-2624.

75 Voladri RK, Lakey DL, Hennigan SH et al.. Recombinant expression and characterization of the major betalactamase of Mycobacterium tuberculosis. Antimicrob Agents Chemother, 1998; 42: 1375-1381.

76 Shepard CC, Van Landingham RM, Walker LL, Good RC. Activity of selected beta-lactam antibiotics against Mycobacterium leprae. Int J Lepr Other Mycobact Dis, 1987; 55: 322-327.

77 Randhawa B, Harris EB, Prabhakaran K. Bactericidal action of oral ampicillin/sulbactam against Mycobacterium leprae. J Antimicrob Chemother, 1999; 44: 279-281.

78 Gelber RH. The activity of amoxicillin plus clavulanic acid against Mycobacterium leprae in mice. J Infect Dis, 1991; 163: 1374-1377.

79 Tseng T-T, Gratwick KS, Kollmann J et al. The RND permease superfamily: an ancient, ubiquitous and diverse family that includes human disease and develoment proteins. J Mol Microbiol Biotechnol, 1999; 1: 107-125.

${ }^{80}$ Braibant M, Gilot P, Content J. The ATP binding cassette (ABC) transport systems of Mycobacterium tuberculosis. FEMS Microbiol Rev, 2000; 24: 449-467.

81 Guilfoile PG, Hutchinson CR. A bacterial analog of the mdr gene of mammalian tumor cells is present in Streptomyces peucetius, the producer of daunorubicin and doxyrubicin. Proc Natl Acad Sci USA, 1991; 88: 85538557.

82 Ainsa JA, Blokpoel MCJ, Otal I et al. Molecular cloning and characterization of Tap, a putative multidrug efflux pump present in Mycobacterium fortuitum and Mycobacterium tuberculosis. J Bacteriol, 1998; 180: 5836-5843.

83 Silva PE, Bigi F, de la Paz Santangelo M et al. Characterization of P55, a multidrug efflux pump in Mycobacterium bovis and Mycobacterium tuberculosis. Antimicrob Agents Chemother, 2001; 45: 800-804.

${ }^{84}$ Doran JL, Pang Y, Mdluli KE et al. Mycobacterium tuberculosis efpA encodes an efflux protein of the QacA transporter family. Clin Diag Lab Immunol, 1997; 4: 23-32.

85 Wilson M, de Risi J, Kristensen H-K et al. Exploring drug-induced alterations in gene expression in Mycobacterium tuberculosis by microarray hybridization. Proc Natl Acad Sci USA, 1999; 96: 6854-6859.

86 de Rossi E, Branzoni M, Cantoni R et al. mmr, a Mycobacterium tuberculosis gene conferring resistance to small cationic dyes and inhibitors. J Bacteriol, 1998; 180: 6068-6071.

87 Stover CK, Pham XQ, Erwin AL et al. Complete genome sequence of Pseudomonas aeruginosa PA01, an opportunistic pathogen. Nature, 2000; 406: 959-964.

${ }^{88} \mathrm{Li} \mathrm{XZ}$, Nikaido H, Poole K. Role of mexA-mexB-oprM in antibiotic efflux in Pseudomonas aeruginosa. Antimicrob Agents Chemother, 1995; 39: 1948-1953.

$89 \mathrm{Ma} \mathrm{D}$, Cook DN, Alberti M et al. Genes acrA and acrB encode a stress-induced efflux system of Escherichia coli. Mol Microbiol, 1995; 16: 45-55.

90 Camacho LR, Ensergueix D, Perez E et al. Identification of a virulence gene cluster of Mycobacterium tuberculosis by signature-tagged transposon mutagenesis. Mol Microbiol, 1999; 34: 257-267.

91 Cox JS, Chen B, McNeil M, Jacobs WR Jr. Complex lipid determines tissue-specific replication of Mycobacterium tuberculosis in mice. Nature, 1999; 402: 79-83.

92 Stover CK, Warrener P, VanDevanter DR et al. A small-molecule nitroimidazopyran drug candidate for the treatment of tuberculosis. Nature, 2000; 405: 962-966.

93 Grebe TW, Stock JB. The histidine protein kinase superfamily. Adv Microb Physiol, 1999; 41: 139-227.

94 Fsihi H, De Rossi E, Salazar L et al. Gene arrangement and organisation in a $\sim 76$ kilobase fragment encompassing the oriC region of the chromosome of Mycobacterium leprae. Microbiology, 1996; 142: 3147-3161. 
95 Barrett JF, Goldschmidt RM, Lawrence LE et al. Antibacterial agents that inhibit two-component signal transduction systems. Proc Natl Acad Sci USA, 1998; 95: 5317-5322.

96 Hlasta DJ, Demers JP, Foleno BD et al. Novel inhibitors of bacterial two-component systems with gram positive antibacterial activity: pharmacophore identification based on the screening hit closantel. Bioorg Med Chem Lett, 1998; 8: 1923-1928. 